\title{
Religious coping strategies and perceived causes of sickness and health in South Africa
}

\begin{tabular}{|c|c|}
\hline \multicolumn{2}{|c|}{$\begin{array}{l}\text { Authors: } \\
\text { Peet J. van Dyk }{ }^{1} \\
\text { Alta C. van Dyk }{ }^{2}\end{array}$} \\
\hline \multicolumn{2}{|c|}{$\begin{array}{l}\text { Affiliations: } \\
{ }^{1} \text { Department of Biblical and } \\
\text { Ancient Studies, University of } \\
\text { South Africa, South Africa }\end{array}$} \\
\hline \multicolumn{2}{|c|}{$\begin{array}{l}\text { 2Department of Psychology, } \\
\text { University of South Africa, } \\
\text { South Africa }\end{array}$} \\
\hline \multicolumn{2}{|c|}{$\begin{array}{l}\text { Correspondence to: } \\
\text { Peet van Dyk }\end{array}$} \\
\hline \multicolumn{2}{|c|}{$\begin{array}{l}\text { Email: } \\
\text { vdykpj1@unisa.ac.za }\end{array}$} \\
\hline \multicolumn{2}{|c|}{$\begin{array}{l}\text { Postal address: } \\
\text { PO Box 911, Pretoria 0043, } \\
\text { South Africa }\end{array}$} \\
\hline \multicolumn{2}{|c|}{$\begin{array}{l}\text { Dates: } \\
\text { Received: } 21 \text { Jan. } 2015 \\
\text { Accepted: } 04 \text { Sept. } 2015 \\
\text { Published: } 03 \text { Nov. } 2015\end{array}$} \\
\hline \multicolumn{2}{|c|}{$\begin{array}{l}\text { How to cite this article: } \\
\text { Van Dyk, P.J. \& Van Dyk, } \\
\text { A.C., 2015, 'Religious coping } \\
\text { strategies and perceived } \\
\text { causes of sickness and health } \\
\text { in South Africa', Verbum et } \\
\text { Ecclesia } 36(1), \text { Art. \#1409, } \\
7 \text { pages. http://dx.doi. } \\
\text { org/10.4102/ve.v36i1.1409 }\end{array}$} \\
\hline \multicolumn{2}{|c|}{$\begin{array}{l}\text { Copyright: } \\
\text { (C) 2015. The Auth } \\
\text { Licensee: AOSIS } \\
\text { OpenJournals. This } \\
\text { licensed under the } \\
\text { Commons Attribut } \\
\text { License. }\end{array}$} \\
\hline \multicolumn{2}{|l|}{ Read online: } \\
\hline 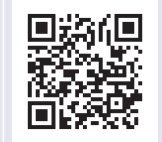 & $\begin{array}{l}\text { Scan this QR } \\
\text { code with your } \\
\text { smart phone or } \\
\text { mobile device } \\
\text { to read online. }\end{array}$ \\
\hline
\end{tabular}

The purpose of this survey was to explore religious coping strategies and to what extent black South Africans directly attributed their health and/or diseases to supernatural forces such as the ancestors and magic. A total of 3000 structured questionnaires were distributed to South Africans of all ethnicities, of which 575 were received back, but only those received from black participants (411) were considered for this study. The SPSS 21 statistical program was used to analyse the data. The results of the study suggest that Mbiti's remark that health and disease in Africa are seen primarily within a religious (i.e. supernatural) framework still holds true for the black South African participants in this study. More than $80 \%(81.5 \%)$ of the participants attributed their health and diseases primarily to the ancestors and magic, whilst only $16.1 \%$ of the participants ascribed any importance to natural causes of diseases (e.g. germs and unprotected sex). These beliefs were especially strong amongst city or town dwellers, people of higher educational level and members of so-called 'mainline' churches (i.e. members of non-Zionist churches).

Intradisciplinary and/or interdisciplinary implications: The article is interdisciplinary in nature covering the following fields: religion, psychology; health studies.

\section{Introduction}

More than four decades ago the east African theologian John Mbiti has argued that in Africa health and disease are seldom seen only in terms of natural causes, but are most often interpreted within a religious framework and thus attributed to supernatural causes (Mbiti 1969:165, 195). He thereby implied that health beliefs of people can only be understood in terms of their worldview or cosmology, which can broadly be defined as people's beliefs and assumptions about the world. It thus acts as a conceptual framework in terms of which people interpret reality (Van der Merwe 2008:57).

The African worldview can be summarised as follows:

According to the African worldview, reality is seen as a closed system in which everything hangs together and all aspects are affected by any change in the system. In this closed system there is a hierarchy with God at the apex, followed by the ancestors, then humankind, and the animals. This is in contrast to the Western worldview, in which reality is seen as consisting of two separate spheres: the natural (physical) and supernatural (metaphysical). (Van der Merwe 2008:65-66, [author's own emphasis])

According to Cottingham (2003:13), religious beliefs form the centre of this vast web of beliefs, attitudes and feelings, which together constitute a worldview. Religious views are therefore of critical importance when considering worldviews and health beliefs, because 'different worldviews may cause different definitions of illness and health' (Van der Merwe 2008:61).

If the traditional African worldview is taken seriously in the health care context, it would therefore imply that the causes of health and illness would not be seen as either natural or supernatural, but rather as both. For example, even if it is recognised that malaria may be caused by a mosquito (natural cause), the traditional African would nonetheless ask which supernatural force used the mosquito as an instrument to cause the disease. Religious beliefs (including the belief in magic and the controlling role of ancestors) should therefore always be taken seriously when considering health issues and prevention programmes in Africa.

In the current Aids pandemic and Ebola crisis, human vulnerability to diseases, as well as the possible harmful effects of traditional rituals and beliefs, has again become prominent worldwide. Within the African context (where the effects of Aids and Ebola are most pronounced) health beliefs (and by extension the perceived effectiveness of medicine and herbs) are therefore of special significance. Health beliefs may play an important role as contributing factors in the spread of 
diseases, especially if such beliefs deny or neglect physical causes as instrumental in the spreading of pathogens.

One of the questions this study wanted to answer is to what extent traditional health beliefs (linked to the African worldview) has been eradicated by westernisation and scientific training in South Africa. Or does Jahoda's earlier finding (1968:1356) still hold water that scientific training does not necessarily eradicate traditional beliefs concerning supernatural causes for diseases?

In a previous article (which formed part of this larger survey) the perceived role of God in health and disease was investigated amongst South Africans of all religions and ethnic backgrounds. The results suggested that God (probably perceived as a high or distant God) was not considered as a major causal factor in terms of general health and was seldom perceived as playing an active role in causing diseases (Van Dyk \& Van Dyk 2014). This finding, however, does not necessarily imply an increasing secularisation amongst specifically black South Africans, but rather suggests that other supernatural forces (specifically the ancestors and magic) may be seen as important causal agents in terms of health and disease.

The purpose of this article is to explore the possible role of such other supernatural agents (specifically the ancestors and witchcraft or magic) as perceived causal agents of health and disease, and more specifically, how these perceptions may play a role in the religious coping strategies of individuals. Only the health beliefs of black South Africans, living both in traditional and urbanised communities, were considered for the purpose of this article, because the beliefs in the controlling effect of ancestors and magic are especially prevalent in black African communities (cf. Niehaus 2001; McNeill \& Niehaus 2009).

Next we will consider the possible ways in which people may resort to religious beliefs when confronted with stressful situations, more specifically during a health crisis.

\section{Coping strategies within a religious framework}

The important role that religion may play in helping individuals in coping with various stressful situations has been suggested by various researchers (e.g. Phelps et al. 2009:1140-1147; Koenig, King \& Carson 2012:93). According to Pargament et al. (1988:90-104; also see Pargament 1997), religious coping strategies can be divided into three possible styles, which may be more or less effective in problemsolving and coping. These can be named as follows: (1) A deferring style, where the believer 'passively' waits for a solution from God. This style can be classified as falling more into the external locus of control end of the spectrum (cf. Wallston, Wallston \& DeVellis 1978:160-170 for the development of the multidimensional health locus of control scale). (2) A collaborative style, which involves an active exchange between believer and God, where both parties collaborate towards the eventual outcome. This style was judged be the researchers to be more effective and to be associated with an internalized commitment by the believer and therefore closer towards the internal locus of control side of the spectrum. (3) A self-directing style, where believers believe that they were given the freedom by God to direct their own lives. This is an active (and more secular) style, falling completely within the internal locus of control side of the spectrum. Both styles (2) and (3) were judged by the researchers to be more effective as coping and problemsolving styles than the deferring style.

It can therefore be concluded that the resort to religion (including the belief in magic and in ancestors) to help cope with stressful situations can either have a positive or negative effect, depending on the coping style chosen by the believers. As mentioned above, it is especially external locus of control coping styles that are not seen as very effective. The logical link between the belief in supernatural forces (specifically the belief in magic, witchcraft and ghosts or spirits) and external locus of control has been argued by Adorno et al. as long ago as 1950. According to them, the belief in such supernatural forces (which they still call 'superstitions ${ }^{\prime 1}$ ) '... indicates a tendency to shift responsibility from the individual onto outside forces beyond one's control' (Adorno et al. 1950:236; also Scheidt 1973:1159).

One can therefore conclude that within a larger religious framework (which may include the belief in magic and the controlling role of the ancestors) believers may choose different styles of problem-solving and coping, and that the belief in magic and the controlling effect of the ancestors tends to predispose such believers towards the external locus of control category: By believing that external agents (over which they have no, or very limited control) may significantly influence their health, they would necessarily limit their own control over such factors. Such health beliefs are important determinants of behaviour change within the health care environment, in so far as they influence the perceptions of patients with regard to the effectiveness of prevention strategies, medical care and medications (cf. Langlie 1977:244-260; Lau, Quadrel \& Hartman 1990:240-259).

\section{Method}

An empirical survey was conducted in 2011 and 2012 amongst the South African population from various backgrounds and geographical locations. The survey formed part of a larger study regarding health beliefs and how such beliefs may inform our health care system (Van Dyk \& Van Dyk 2014). However, because the focus of this article is on traditional African health beliefs, only the data from black South Africans were considered for this article.

1.It is now generally accepted by scholars of religion that the clear distinction between religion and magic (as advocated by earlier scholars such as Tylor [1924] and Frazer [1957]) is not tenable. This inseparable mixture of magic and religion is especially [1957]) is not tenable. This inseparable mixture of magic and religion is especially
obvious in Egyptian religion, which is basically magical in its outlook (Pinch 1994:12). obvious in Egyptian religion, which is basically magical in its outlook (Pinch 1994:12).
Both so-called religion and magic assumes the possibility of a supernatural system Both so-called religion and magic assumes the possibility of a supernatural system
of causes and effects, which is regarded by the believer as just as real as any physical cause and effect (cf. Van Dyk 2010:380-383; Mocan \& Pogorelova 2013:3-4). 


\section{Research design and sample}

A quantitative research design consisting of questionnaires was used to conduct the research. Due to the extra-ordinary size of the population - the mid 2014 estimates of the black South African population was 43 million people (Statistics South Africa 2014) - and also due to financial constraints, a quantitative research design was deemed the only practical possibility. A quantitative survey also enabled the researchers to access a larger number of potential participants.

Questionnaires were sent to approximately 3000 Psychology students at the University of South Africa as part of a noncompulsory assignment in which they were requested to act as voluntary field workers. They were explicitly requested NOT to fill in the questionnaires themselves, but to give the questionnaire to two people from different backgrounds and educational levels within their community (Van Dyk \& Van Dyk 2014). ${ }^{2}$ In addition to this, Zulu field workers were trained to conduct a survey with the same questionnaires in rural KwaZulu-Natal, South Africa. The sample could be described as a convenience sample (cf. Coolican 2004:42) (also see Van Dyk \& Van Dyk 2014). ${ }^{3}$

Participants were assured that their anonymity would be protected and they were requested not to write their names on the completed questionnaires, while fieldworkers were asked to seal the completed questionnaire in an envelope (in the presence of the participant) and send them to the researchers without opening them (Van Dyk \& Van Dyk 2014). The research was approved by the Ethics Committee of the Department of Psychology, Unisa.

\section{Measuring instrument: Structured questionnaire}

A structured questionnaire was used for the survey where participants had only to mark the answer of their choice. Participants were explicitly instructed that there are no right or wrong answers, but that the purpose of the survey was to determine their own personal opinions and beliefs. The following information was obtained from the questionnaire (Van Dyk \& Van Dyk 2014).

(1) Demographical information (i.e. age, gender, place of residence, home language, highest academic qualification, occupation and religion). (2) Likert scales (ordinal threepoint scales, ranging from 'agree' to 'disagree') were used to measure participants' religious and health beliefs (Van Dyk \& Van Dyk 2014). Three categories of questions formed part

\footnotetext{
2.It should be stressed that the sample did NOT consist of Psychology students. The results of the survey suggested that the goal to avoid sampling bias was to some extent reached, because the participants came from diverse backgrounds (rural or city), educational levels, and ages, and both genders were adequately represented. As is to be expected the sample was somewhat skewed in terms of higher educational level and by the fact that slightly more women completed the survey than their male counterparts.

3.The ideal of random sampling is seldom achieved in the social sciences, mainly because random or probability samples are expensive and difficult to obtain. The vast majority of research in the social sciences relies on non-probability samples an acceptable method in social sciences (Terre Blanche, Durrheim \& Painter $2006: 133,139)$. We therefore choose to call our sample a convenience sample, rather than a random sample.
}

of this part of the study: (a) Perceived causes of diseases, including Aids, (b) Determinants of health and (c) Perceived power of medicines.

The reliability and validity of the questionnaire are acceptable. Content validity was assessed by asking two colleagues to scrutinise the questionnaire before conducting the survey (Coolican 2004:193). Construct validity was obtained by subjecting the data received from the questionnaire to Factor Analysis (i.e. Principle Component Analysis [PCA]) - see results below - which made it possible to construct three scales and test for the reliability of the data and for construct validity.

\section{Statistical analysis}

The IBM Statistical Package (SPSS 21) was used for descriptive and inferential statistical analysis of the data. The threepoint Likert items were coded to range from +1 (agree) to -1 (disagree). This implies that positive values would indicate agreement with a specific statement, zero values would reflect uncertainty, whilst negative values would reflect disagreement (Van Dyk \& Van Dyk 2014).

The data was subjected to Principle Component Analysis to extract possible scales from the items in the survey. The data adhered to all the requirements for Principle Component Analysis (Kaiser-Meyer-Olkin $=0.899$ and Bartlett's Test of Sphericity Significance $=0.00)$. Based on PCA, two scales (i.e. the Traditional Health Belief Scale [13 items] and the Natural Causes Scale [5 items]) were extracted and calculated by summing the values of the relevant questions and by dividing the result by the number of questions in the scale. This again yielded values for each scale between +1 and -1 . The reliability of the Traditional Health Belief Scale was within acceptable limits (i.e. Cronbach's Alpha $=0.899$ ). Although the reliability of the Natural Causes Scale was relatively low (i.e. Cronbach's Alpha $=0.444$ ) - probably due to the fact that it consisted of five items only - it was nonetheless decided to use it with caution, primarily as a point of comparison with the Traditional Health Belief Scale.

The Traditional Health Belief Scale comprised of 13 Likerttype items, which asked participants whether they agreed, were uncertain or disagreed with attributing ancestors and magic as factors (1) in causing diseases (including Aids), (2) in providing general health, (3) in yielding power to medicines and herbs and (4) in facilitating healing. The scale therefore assessed to what extent black South Africans attributed supernatural causes (excluding God) as important factors in determining health and disease.

The Natural Causes Scale comprised of five items, asking participants if they agreed, was uncertain, or disagreed with the notion that diseases are caused by germs only, if Aids is mainly caused by unprotected sex, if only ARV's can be of help when a person is infected with HIV and if they prefer a Western-trained doctor when they are sick. The scale is 
therefore to some extent the reverse of the Traditional Health Belief Scale by emphasising natural rather than supernatural factors involved in disease and health.

When tested for normality (Kolmogorov-Smirnov test) both scales yielded a significant result, indicating that the scales do not adhere to normality, necessitating the usage of nonparametric tests in analysing the data (i.e. Mann-Withney $U$ tests and Spearman correlation) (cf. Pallant 2013:221; Coolican 2004:363). The level of significance was set at 0.05 (Van Dyk \& Van Dyk 2014).

\section{Results \\ Demographic attributes of participants}

A total of 574 participants returned questionnaires, representing a return rate of $19.1 \%$, but for the purpose of this study only 411 questionnaires (those from black South Africans) were analysed. Of the participants 244 (59.4\%) were women and $166(40.4 \%)$ were men. ${ }^{4}$ The mean age of participants was 34.47 years $(\mathrm{SD}=10.9$; $n=411)$. Almost half of the sample $(49.6 \%)$ lived in rural areas, whilst $50.4 \%$ resided in cities or towns. Educational levels of the participants were as follows: (1) Grade 7 or lower (including no formal education): $11.5 \%$, (2) Grades 8-11: 22.1\%, (3) Matric: 38.7\% and (4) Post-matric qualifications: $26.83 \% .^{5}$

Religious affiliations were broadly classified into two main categories named so-called 'mainline Christian' and 'traditional African' religious affiliations. For the purpose of this study, 'mainline Christian' was defined as not belonging to one of the African Initiated Churches (e.g. Zionist or Shembe), whilst the 'traditional African' group included African Initiated Churches as well as people adhering to traditional African religion. Participants who belonged to non-Christian religions, or who indicated that they were not religious (i.e. a total of 18 participants or $4.4 \%$ ), were excluded in calculations pertaining to religious affiliation. Of the 393 respondents who were included in the calculations, $50.1 \%$ (206) were affiliated to 'mainline Christian' churches, whilst 45.5\% (187) belonged to traditional African religious affiliations (also see Van Dyk \& Van Dyk 2014).

\section{The Traditional Health Belief Scale versus the Natural Causes Scale}

The results of the survey showed that participants (i.e. black South Africans) to a very large degree attributed health and disease to supernatural causes (i.e. specifically the ancestors and magic). The median for the Traditional Health Belief Scale was $+0.65(n=390)$, with a possible range between -1 and +1 . A total of $81.5 \%$ agreed with the view that supernatural

\footnotetext{
4.This slight skewedness towards women was to be expected, due to the fact that the South African population is made up of slightly more women than men $(51.2 \%$ women versus $48.8 \%$ men - 2014 statistics) and the fact that women are generally more willing to complete surveys than men.

5.These results imply that the sample of the study, when compared to the South African population (see Statistics South Africa 2014), was skewed towards more educated and more urbanised participants.
}

factors play a role in health and disease, whilst only $18.5 \%$ of participants were uncertain or disagreed with the notion.

In contrast to the previous result, the median on the Natural Causes Scale was very low (median $=-0.6 ; n=398$ ), with a total of $83.9 \%$ of participants disagreeing with the notion that natural causes are the only (or primary) factors in causing disease or health. An especially disturbing result was that $78.3 \%$ of the participants disagreed with one of the items in the scale, that is, the notion that Aids is primarily caused by unprotected sex.

It can therefore be concluded that the results for the two scales showed that more than $80 \%$ of black South Africans participants believe that, contrary to the secular Western Medical Model, health and disease are mainly caused by the ancestors and magic and not primarily by natural causes such as germs, or high-risk behaviour.

\section{Inter-group differences}

No significant inter-group differences for the Traditional Health Belief Scale or the Natural Causes Scale were observed for gender or age. However, some inter-group differences for the two scales were observed for religious affiliation, educational level and place of residence.

\section{'Mainline' versus traditional African religious affiliations}

The Mann-Whitney test showed that both members of 'mainline' churches and members of traditional African religious affiliations believed that disease and health were caused by the ancestors and magic (rather than by natural causes). However, members of 'mainline' churches believed significantly more in such supernatural causes and significantly less in natural causes than members of traditional religious affiliations (see Table 1).

These results were somewhat unexpected, because one may have suspected that members of more traditional religious affiliations would be more inclined to emphasise factors such as the ancestors and magic, which are regarded as important causal factors within traditional African societies.

\section{Rural versus city or town dwellers}

Mann-Whitney tests further showed that city or town dwellers believed significantly more in supernatural causes (i.e. specifically the ancestors and magic) and significantly less in natural causes than rural inhabitants (see Table 2). Thus, although both groups were inclined to attribute health

TABLE 1: Differences between religious affiliations.

\begin{tabular}{lll}
\hline Religious affiliation & Supernatural causes & Natural causes \\
\hline 'Mainline' churches & Median $=+0.85(n=196)$ & Median $=-0.6(n=201)$ \\
Traditional affiliations & Median $=+0.38(n=176)$ & Median $=-0.4(n=179)$ \\
Mann-Whitney & $\begin{array}{l}U=8492.5 ; Z=-8.497 ; \\
p=0.000\end{array}$ & $\begin{array}{l}U=15081.5 ; Z=-2.762 ; \\
p=0.006\end{array}$ \\
\hline
\end{tabular}


TABLE 2: Differences between rural versus city or town dwellers.

\begin{tabular}{lll}
\hline Religious affiliation & Supernatural causes & Natural causes \\
\hline City or town & Median $=+0.77(n=195)$ & Median $=-0.6(n=201)$ \\
Rural & Median $=+0.54(n=195)$ & Median $=-0.4(n=197)$ \\
Mann-Whitney & $\begin{array}{l}U=12778.5 ; Z=-5.629 ; \\
p=0.000 ;\end{array}$ & $\begin{array}{l}U=15623.0 ; Z=-3.695 ; \\
p=0.000\end{array}$ \\
\hline
\end{tabular}

and disease to the ancestors and magic (rather than to natural causes) city or town dwellers generally felt stronger about their beliefs.

These results therefore suggest that, like members of 'mainline' churches, participants living in cities and towns leaned significantly more towards attributing health and disease to the ancestors and to magical forces than participants living in rural areas.

\section{Educational level}

A Spearman correlation revealed that there was a significant positive correlation between the Traditional Health Belief Scale and educational level (Spearman Rho $=+0.256$; $p=0.000 ; n=387)$. This suggests that people with higher educational levels were more inclined towards attributing their health and diseases to the ancestors than people with lower educational levels. Like the previous two results this outcome may to some extent be seen as counter-intuitive (Mocan \& Pogorelova 2013:29).

No significant negative correlation between the Natural Causes Scale and educational level was evident ( $R h o=-0.062$; $p=0.217)$. This lack of a significant correlation may either be because of the rather low internal consistency of the scale (Cronbach's Alpha $=0.444)$, or it may be an indication that a more complex relationship exists between the Traditional Health Belief Scale and the Natural Causes Scale in the sense that the one view may not necessarily completely exclude the other one. This suggests, as mentioned in the introduction, that participants did not view supernatural causes and natural causes necessarily as opposites (as would be the case within a western worldview).

\section{Discussion and conclusion}

The results of the study suggest that Mbiti's remark that health and disease in Africa are seen primarily within a religious (i.e. including supernatural forces) framework still holds true for the black South African participants in this study. More than $80 \%(81.5 \%)$ of the participants attributed their health and diseases primarily to the ancestors and magic, whilst only $16.1 \%$ of the participants attributed any importance to natural causes of diseases (e.g. germs and unprotected sex). This result suggests that so-called natural causes of illness were considered as relatively unimportant, in relation to the all-important role played by supernatural causes.

If health care workers were therefore to focus primarily (or exclusively) on physical causes of diseases (such as Aids) their advice and suggested prevention programmes would seem largely irrelevant to many or even most black South Africans.

The above problem begs the difficult questions about cultural relativism and the possibility of a respectful dialogue between religion and a mostly secularised public health system (cf. De Gruchy 2007:7-12). According to the relativistic view in anthropology, no culture can be viewed as superior to another culture, but should be appreciated for its own uniqueness.

Along these lines, Amutabi (2008:151-153) severely criticised Western scholars for regarding traditional health beliefs as 'primitive and based on superstition'. For example, he regards the early east African historian W.O. Henderson's view (quoted by Amutabi 2007:151) that Africans often resort to witchcraft to combat disease as 'based on a basic ignorance of African healing systems'. He further asks why only those health practices which are 'sanctioned by Western culture' are considered to be valid, whilst 'anything else was backward and savage'.

Amutabi then argued against these notions of western superiority by saying:

... postcolonial scholars have been trying ... to show that traditional African medicine was based on sound and scientific knowledge but also that they are efficacious. Europeans rejected African medical knowledge because they were ignorant about it, and because it did not conform to their cosmologies. (Amutabi 2008:151-152, [author's own emphasis])

Although Amutabi's criticism of the assumed superiority of Western cultures should be applauded and no culture should be so arrogant to assume that they have all the wisdom whilst regarding others as backward, one should nonetheless ask to what extent certain elements of cultures (e.g. traditional health practices) should indeed be assessed in terms of their scientific soundness. Amutabi apparently accepts that scientific knowledge should be universal and not be regarded as merely a Western invention (see highlighted section in the quotation above). If this fact is conceded, then a scientific evaluation of, for example the effectiveness of traditional African herbs, should not be criticised as a form of Western sanctioning.

Amutabi's generalising view that African medicine was based on 'sound and scientific knowledge' is also highly questionable. Although it is increasingly recognised by global pharmaceutical companies that traditional African herbs should be scientifically investigated for their possible medicinal value, and whilst it has been demonstrated that in some cases such herbs indeed have beneficial qualities, this fact cannot be generalised to all African herbs or health practices. Not only traditional black African medicine were or are subjected to scientific scrutiny. With the development of the scientific method traditional European medicine were also rigorously subjected to scientific trails before being used in modern pharmacology. Another example was the once popular health practices and traditions of the Afrikaner 
people (so-called 'boere rate') in South Africa. As was the case with most such traditional medicine, some of them were found to have some real pharmacological merit, whilst most had to be abandoned because of their inefficacy or even harmful effects.

Independent of the chemical properties or supposed magical properties of traditional herbs, one should further consider the possible placebo effect of traditional herbs as well as the psychosomatic benefits of religious rituals (Scorgie 2008:83-106). Some religions also promote healthy lifestyles (e.g. they frown upon excessive alcohol consumption and smoking) and promote good eating habits (e.g. the avoidance of pork which may, in uncontrolled situations, be infected with nematodes, which may cause Trichinosis, if not cooked properly). The positive psychosomatic effects of traditional medicines and rituals and the promotion of healthy lifestyles by certain religions are therefore well-recognised (cf. Koenig et al. 2012:604)

As mentioned earlier, the belief in the supernatural causes of illness, which were especially strong amongst city or town dwellers, people of higher educational level and members of so-called 'mainline' churches (i.e. members of non-Zionist churches), could be viewed as counter-intuitive. From an anthropological perspective, Van Vuuren (pers. comm., 13 November 2014) suggested that these results may be explained in terms of the high stress levels currently experienced by many South Africans. According to Van Vuuren, it is especially the better educated black South Africans, living mostly in cities and towns, who are currently struggling to cope in the increasingly complex work and financial situation, whilst often also struggling with health issues. Coping in such a changing and complex society may therefore necessitate special coping strategies, including a possible resort to religious coping strategies. ${ }^{6}$

The results of the study suggested that black participants are resorting to religion as a way of coping with their stressful lives, especially in the sphere of health and disease. Amongst the participants by far the most important religious coping strategy was what Pargament et al. (1988:90-104) called the 'deferring style'. This religious coping style is an example of external locus of control. Although Pargament et al. (1988:90-104) judge this coping style as not being very effective it does have the psychological effect of denying own responsibility (and possibly stigmatisation in the case of Aids), by largely shifting the domain of health and disease outside one's own control by attributing them to external supernatural forces.

Given the results of this survey, one possible recommendation could be to increase the level of scientific training amongst South Africans so that they could better understand the possible physical causes of diseases. However, as already demonstrated by Jahoda (1968:1356) and confirmed by this study, higher education levels do not necessarily eradicate traditional beliefs in supernatural causal factors, at least not in the short term. In the short term the only possible solution would therefore be to find ways to accommodate the traditional beliefs in supernatural causal factors by many black South Africans, whilst still emphasising own responsibility, that is, to try and cultivate a more 'collaborative style' of coping (Pargament et al. 1988:90-104). Such a coping style (within the health care situation) should emphasise the fact that people can at least to some extent have control over their health and prevent diseases by avoiding highrisk behaviour and by the usage of effective medicine. Such an approach would not necessarily exclude non-harmful religious practices such as cleansing rituals and prayers.

The remaining question is to what extent the African magicomythical cosmology is compatible with our modern scientific cosmology and can thus be maintained in the long run. This dilemma traditional Africans are facing now in trying to reconcile their pre-scientific cosmology with the modern scientific cosmology, is not unique. Ancient Greece also struggled with reconciling more controlled observations of the natural world with the pre-scientific views of the cosmology of the Ancient Near East. Similarly Europeans, coming out of the Middle Ages with its pre-scientific and magico-mythical cosmology (very similar to the African cosmology), also faced the dilemma of how to reconcile their traditional pre-scientific cosmology with the findings of modern science. The way black Africans choose to handle this dilemma cannot be prescribed to them by other cultures, and any possible future changes in cosmology would involve a revolutionary switch in paradigms (Kuhn 1962).

Due to the nature of the research (quantitative research on a convenience sample) the results cannot necessarily be generalised to the general population of black South Africans. However, the agreement of the results of this study with the general tendencies suggested by previous research amongst black African populations (c.f. Beuster 1997:4-16; Bodibe 1992:149-165; Hammond-Tooke 1989 and Mbiti $1969: 165,195)$ indicate that the results may reflect the views of a significant part of black South Africans. Additional studies (including qualitative studies) are necessary to further explore religious coping strategies among black South Africans.

\section{Acknowledgements Competing interests}

The authors declare that they have no financial or personal relationships which may have inappropriately influenced them in writing this article.

\section{Authors' contributions}

A.C.v.D. (University of South Africa) was responsible for the psychological perspectives and statistical analysis and P.J.v.D. (University of South Africa) was responsible for the religious perspectives. 


\section{References}

Adorno, T.W., Frenkel-Brunswik, E., Levenson, D.J. \& Sanford, R.N., 1950, The authoritarian personality, Harper, New York, NY.

Amutabi, M.N., 2008, 'Recuperating traditional pharmacology and healing among the Abaluyia of western Kenya', in T. Falola \& M.M. Heaton (eds.), Health knowledge and belief systems in Africa, pp. 149-170, Carolina Academic Press, Durham, NC.

Beuster, J., 1997, 'Psychopathology from a traditional Southern African perspective', Unisa: Psychologia 24(2), 4-16.

Bodibe, R.C., 1992, 'Traditional healing and indigenous approaches to mental health problems', in I. Uys (ed.), Psychological counseling in the South African context, pp. 149-165, Maskew Miller Longman, Cape Town.

Coolican, H., 2004, Research methods and statistics in psychology, 4th edn., Hodde \& Stoughton, London.

Cottingham, J., 2003, On the meaning of life, Routledge, London.

De Gruchy, S., 2007, 'Taking religion seriously: Some thoughts on "Respectful dialogue" between religion and public Health in Africa', paper presented at the ARHAP International Colloquium 2007, pp. 7-12, viewed 22 June 2015, from http://www.irhap.uct.ac.za/downloads/ARHAP_colloquium2007.pdf

Frazer, J.G., 1957, The golden bough. A study in magic and religion, McMillan, London.

Hammond-Tooke, D., 1989., Rituals and medicines, A.D. Jonker, Johannesburg.

Jahoda, G., 1968, 'Scientific training and the persistence of traditional beliefs among West African university students', Nature 220, 1356. PMID: 5701363, http:// dx.doi.org/10.1038/2201356a0

Koenig, H.G., King, D.E. \& Carson, V.B., 2012, Handbook of religion and health, 2nd edn., Oxford University Press, New York, NY.

Kuhn, T.S., 1962, The structure of scientific revolutions, Chicago University Press, Chicago.

Langlie, J.K., 1977, 'Social networks, health beliefs, and preventative health behaviour', Journal of Health and Social Behavior 18, 244-260. PMID: 903596

Lau, R.R., Quadrel, M.J. \& Hartman, K.A., 1990, 'Development and change of young adults' preventative health beliefs and behaviour: Influence from parents and peers', Journal of Health and Social Behavior 31, 240-259. PMID: 2133479

Mbiti, J.S., 1969, African religions and philosophy, Heinemann, London.

McNeill, F.G. \& Niehaus, I., 2009, 'Magic', in AIDS Review 2009, n.p., Centre for the Study of AIDS, University of Pretoria.
Mocan, N. \& Pogorelova, L., 2013, 'Compulsory schooling laws and formation of beliefs: Education, religion and superstition' NBER Working Paper Series, Working Paper 20557, 1-64. http://dx.doi.org/10.3386/w20557

Niehaus, I., 2001, Witchcraft, power and politics. Exploring the occult in the South African Lowveld, David Philip, Cape Town.

Pallant, J., 2013, SPSS survival manual: A step by step guide to data analysis using SPSS for Windows, 5th edn., McGraw Hill, Berkshire.

Pargament, K.I., 1997, The psychology of religion and coping. Theory, research, practice, Guilford Press, New York, NY.

Pargament, K.I., Kennell, J., Hathaway, W., Grevengoed, N. \& Jones, W., 1988, 'Religion and the problem-solving process. Three styles of coping', Journal for the Scientific Study of Religion 27(1), 90-104. http://dx.doi.org/10.2307/1387404

Phelps, A.C., Maciejewski, P.K., Nilsson, M., Balboni, T.A., Wright, A.A., Paulk, M.E. et al., 2009, 'Religious coping and use of intensive life-prolonging care near death
in patients with advanced cancer', JAMA 301(11), 1140-1147. PMID: 19293414, http://dx.doi.org/10.1001/jama.2009.341

Pinch, G., 1994, Magic in Ancient Egypt, The British Museum Press, London.

Scheidt, R.J., 1973, 'Belief in supernatural phenomena and locus of control' Psychological Reports 32, 1159-1162. PMID: 4709809, http://dx.doi.org/10.2466/ pr0.1973.32.3c.1159

Scorgie, F., 2008, 'Weapons of faith in a world of illness: Zionist prophet-healers and HIV/AIDS in rural KwaZulu-Natal', in T. Falola \& M.M. Heaton (eds.), Health knowledge and belief systems in Africa, pp. 83-106, Carolina Academic Press, Durham, NC.

Statistics South Africa, 2014, 'Statistical release p0302', viewed 25 August 2015, from www.statssa.gov.za/publications/.../P03022014.pdf

Terre Blanche, M., Durrheim, K. \& Painter, D., 2006, Research in practice. Applied methods for the social sciences, UCT Press, Cape Town.

Tylor, E.B., 1924, Primitive culture, vol. 1, Brentano's Publishers, New York, NY

Van der Merwe, J.C., 2008, 'The relevance of worldview interpretation to health care in South Africa', in T. Falola \& M.M. Heaton (eds.), Health knowledge and belief systems in Africa, pp. 55-66, Carolina Academic Press, Durham, NC.

Van Dyk, P.J., 2010, 'Magic, myth and monotheism when reading Genesis 30:37-39', Old Testament Essays 23(2), 378-405.

Van Dyk, P.J. \& Van Dyk, A.C., 2014, 'What does God have to do with my health?', Verbum et Ecclesia 35(1), Art. \#1313, 6 pages. http://dx.doi.org/10.4102/ve.v35i1. 1313

Wallston, K.A., Wallston, B.S. \& DeVellis, R. 1978, 'Development of the multidimensional health locus of control (MHLC) scales', Health Education \& Behavior 6(1), 160-170. http://dx.doi.org/10.1177/109019817800600107 